\title{
Amide Utilization in Aspergillus nidulans: Evidence for a Third Amidase Enzyme
}

\author{
By M. J. HYNES \\ Department of Genetics and Human Variation, La Trobe University, \\ Bundoora, 3083, Victoria, Australia
}

(Received 24 March 1975; revised 4 June 1975)

\begin{abstract}
SUMMARY
A mutation in a gene designated $g m d A$ has been found to lead to loss of ability of Aspergillus nidulans to use benzamide, phenylacetamide and several other amides as sole nitrogen sources for growth. The gmdAI lesion results in low levels of an enzyme, called the general amidase, which has activity for a wide range of amide substrates. This enzyme is repressed by certain nitrogen-containing metabolites, including ammonium, but is probably not regulated by induction or by carbon catabolite repression. Evidence is presented for the general amidase being distinct from the previously characterized acetamidase and formamidase enzymes. The data also indicate that there is a fourth amidase capable of the hydrolysis of valeramide and hexanamide.
\end{abstract}

\section{INTRODUCTION}

The utilization of amides as carbon and nitrogen sources for growth by Aspergillus nidulans was investigated by Hynes \& Pateman (1970a). Evidence was found for two amidases, one (formamidase) apparently specific for formamide as a substrate, and the other (acetamidase) capable of hydrolysing acetamide and a number of other aliphatic amides. A lesion in the $f m d S$ gene was found to lead to loss of formamidase activity, while amdS mutants were deficient in acetamidase activity (Hynes \& Pateman, I970c; Dunsmuir \& Hynes, 1973).

An amdS, fmdS double mutant was found to utilize benzamide, butyramide and some other amides as sole nitrogen sources, suggesting that there might be other enzymes capable of amide hydrolysis. This has been investigated by looking for mutants with reduced growth on benzamide, and the results indicate that $A$. nidulans has a third amidase enzyme of broad substrate specificity with hydrolytic activity towards both aromatic and aliphatic amides. This enzyme has been called the general amidase.

\section{METHODS}

Strains. The genotypes of strains used are outlined in Table I. Isolation of amdSI7, fmdSI, areAIO2 (formerly amdTIO2) and areAI9 (formerly amdTI9) mutants have been described previously (Hynes \& Pateman, 1970 b, $c$; Hynes, 1972). The areAro2 lesion leads to stronger than wild-type growth on a number of nitrogen sources, such as acetamide, acrylamide, L-leucine, L-histidine and milk protein, but to poorer growth on formamide and uric acid. The are AI 9 lesion leads to poorer than wild-type growth on most nitrogen sources including acetamide, formamide, L-glutamate, L-histidine, uric acid and milk protein 
Table I. Genotypes of strains used

\section{Strain}

Wild type

areAIO2

areAIO2; bzuAt

bzuAI

areAIO2; gmdAI

areAI9

areA102, amdSr7; gmdAr

areAIo2, amdSI 7 , fmdSI ; gmdAI

gmdAI

amdSI 7 gmdAI

amdSI 7 fmdSI; gmdAI

amdSI7

fmdSI

amdSI 7 fmdSI
Genotype*

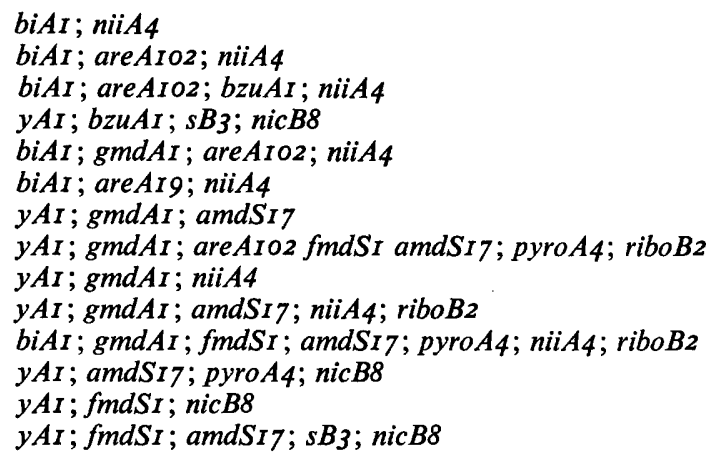

biAt; niiA4

biAI; areAIO2; bzUAI; niiA4

yAI; bzuAI; sB3; nicB8

biAI; gmdAI ; areAIo2; niiA4

biAr; areArg; niiA4

yAI; gmdAI; areAIO2 fmdSI amdSI 7 ; pyroA4; riboB2

$y A I ; g m d A I ; n i i A 4$

yAI; gmdAx; amdSI 7; niiA4; riboB2

biAr ; gmdAI ; fmdSr; amdSI 7 ; pyro $44 ;$ niiA4; riboB2

$y A r ;$ fmdSr; nicB8

$y A I ;$ fmdSI ; amdSI 7 ; sB3; nic B8

* For genotypic symbols, other than those described in the text, see Clutterbuck (1973).

(Hynes, 1973b; Arst \& Cove, 1973; Hynes, 1975a; Polkinghorne \& Hynes, 1975). There is strong evidence for the are $A$ gene being involved in ammonium repression of enzymes of nitrogen catabolism (Arst \& Cove, 1973; Hynes, 1974 $b$, 1975 $a$ ).

Isolation of mutants. Mutants with reduced ability to utilize benzamide as a sole nitrogen source were isolated from the areAroz strain. Conidia of this strain were treated with the mutagen $N$-methyl- $N^{\prime}$-nitro- $N$-nitrosoguanidine by the method described previously (Hynes \& Pateman, 1970 b), and mutants able to grow with ammonium but not with benzamide $\left(\mathrm{IO}^{-2} \mathrm{M}\right)$ as the sole nitrogen source were isolated using the replica-plating method of Mackintosh \& Pritchard (I963).

Media. The glucose (I \%, w/v), nitrogen-free minimal medium ( $-\mathrm{N}$ medium) of Cove (I966) was used. Carbon and nitrogen-free medium ( $-\mathrm{CN}$ medium) was the above medium with glucose omitted. Carbon and nitrogen sources were added to this medium as required.

Growth of mycelium. Mycelium was grown at $30{ }^{\circ} \mathrm{C}$ in $200 \mathrm{ml}$ of medium in Il flasks in a Gallenkamp orbital incubator and harvested by filtration through nylon net. Mycelium was pressed dry between towelling paper and used immediately to prepare crude extracts.

Extracts. Crude extracts of mycelium for enzyme assays were prepared by grinding with ice-cold $0.1 \mathrm{M}$-orthophosphate buffer $\mathrm{pH} 7.2$ and glass beads in a cold mortar and pestle. The resulting slurry was centrifuged for $30 \mathrm{~min}$ at $40000 \mathrm{~g}$ in a Sorvall $\mathrm{RC}_{2} \mathrm{~B}$ centrifuge at $4{ }^{\circ} \mathrm{C}$. The protein concentration present in the extract was determined by the Folin method (Lowry et al. I95I).

Amidase enzyme. Assays were performed using the method of Hynes (1970) with the modification that all amide substrate solutions were made in $0 \cdot \mathrm{I}$ M-orthophosphate buffer $\mathrm{pH} 7 \cdot 2$. The amide substrate concentration was $\mathrm{IO}^{-2} \mathrm{M}$ with the exception of acetamide $\left(2 \times 10^{-2} \mathrm{M}\right)$.

Thermal inactivation studies. Samples ( $\mathrm{I} \mathrm{ml}$ ) of extracts were added to test tubes and heated in a water bath maintained at $44{ }^{\circ} \mathrm{C}$ for various time intervals before rapid cooling in ice. Amidase determinations were then carried out on these extracts.

Starch gel electrophoresis. Electrophoresis was carried out with a starch concentration of $\mathrm{I} 2 \%(\mathrm{w} / \mathrm{v})$ and the discontinuous buffer system of Gahne (I963). The gel was run at $600 \mathrm{~V}$ for $4 \mathrm{~h}$ at $4{ }^{\circ} \mathrm{C}$. Amidase activity on gel slices was stained by placing a filter paper soaked in amide solution (acetamide, $2.5 \times 10^{-1} \mathrm{M}$; butyramide, $5 \times 10^{-2} \mathrm{M}$; benzamide, $2 \times 10^{-2} \mathrm{M}$ ) on the surface of a freshly sliced gel for 5 to $15 \mathrm{~min}$. The filter paper was removed and 
replaced with one saturated with Nessler's reagent. The appearance of brown zones on this filter paper due to release of $\mathrm{NH}_{4}{ }^{+}$from the amide indicated the position of amidase act ivity

Chemicals. The following amides were used: acetamide (Merck), formamide (Ajax Chemicals Ltd, Sydney), $n$-butyramide and $n$-valeramide (K \& K Laboratories), $n$-hexanamide (Eastman Organic Chemicals), and benzamide, proprionamide, and phenylacetamide (Fluka). Other amides were obtained from Sigma. Benzamide and phenylacetamide were recrystallized once from hot water. Starch was obtained from Electrostarch Co., Madison. Wisconsin, U.S.A. Other chemicals were of reagent grade.

\section{RESULTS}

\section{Initial characterization of mutants}

Mutants with reduced ability to grow on medium containing benzamide as the sole nitrogen source were isolated from the areAro2 strain (see Methods). The areA102 strain was chosen as the parent strain since this strain was found to utilize benzamide more readily than wild type and therefore allowed more efficient mutant selection. Eleven mutants were isolated. Most had a phenotype of growth inhibition by benzamide, and their growth was reduced when acetate was the sole carbon source. These mutations were located in at least six loci and have been briefly described elsewhere (Hynes, 1975b). Two of the mutants had a phenotype in which amide utilization only was affected and these were therefore investigated in detail. For each mutant a single gene mutation was shown to determine the observed phenotype. The effects of both lesions could be observed in both are $A^{+}$and are Aroz backgrounds (see Table 2).

The contrasting growth properties of the two mutants are summarized in Table 2. The bzuAI mutation resulted in reduced growth on benzamide when it was the sole carbon and nitrogen source. The utilization of phenylacetamide (and other amides) and the aromatic amino acids, L-tyrosine and L-phenylalanine, as nitrogen sources was not affected by $b z u A I$. In addition, $b z u A I$ strains were unable to utilize sodium benzoate as a sole carbon source. These effects of $b z u A I$ were recessive in heterozygous diploids. Benzamidase activity was not affected in the areAro2; bzuAI strain (Table 3).

Haploidization analysis (McCully \& Forbes, 1965) showed that $b z u A I$ was located in linkage group IV, and approximately $22 \%$ recombination with mauA2 (Arst \& Cove, I969) was detected in sexual crosses.

Strains containing gmdAI grew poorly on benzamide, phenylacetamide and some other amides as sole nitrogen sources (see below). In contrast to $b z u A I$, the gmdAI lesion did not affect growth on benzamide or benzoate as sole carbon source. The effects of gmdAI were recessive in heterozygous diploids. The gmdA gene has been assigned to linkage group II by haploidization. It is shown below that the $g m d A r$ mutation causes low benzamidase activity.

\section{Regulation of benzamidase and phenylacetamidase activity}

The ability of crude extracts of various strains to hydrolyse benzamide and phenylacetamide was investigated (Table 3). The specific activities found in these experiments were somewhat higher than those found later (Table 5). The reasons for this discrepancy are not known.

The areAIO2 mutation resulted in higher benzamidase and phenylacetamidase activity than present in the wild-type strain. This correlated with better growth of areAroz than wild type on benzamide and phenylacetamide as nitrogen sources (Table 2). Moreover, are $A 19$ and some other are $A$ strains are unable to use these amides as sole nitrogen sources 
Table 2. Growth properties of mutants affecting benzamide utilization

Growth is represented by symbols in order of decreasing growth:,,,+++ \pm- . Symbols on different media are not equivalent.

\begin{tabular}{|c|c|c|c|c|}
\hline \multirow[b]{2}{*}{ Strain } & \multicolumn{2}{|c|}{ Nitrogen source* } & \multicolumn{2}{|c|}{ Carbon source $\dagger$} \\
\hline & $\begin{array}{c}\text { Benzamide } \\
\left(10^{-2} \mathrm{M}\right)\end{array}$ & $\begin{array}{l}\text { Phenylacetamide } \\
\left(\mathrm{IO}^{-2} \mathrm{M}\right)\end{array}$ & $\begin{array}{c}\text { Benzamide } \\
\left(\mathrm{IO}^{-2} \mathrm{M}\right)\end{array}$ & $\begin{array}{c}\text { Sodium benzoate } \\
(0.5 \%)\end{array}$ \\
\hline Wild type & + & + & + & + \\
\hline $\begin{array}{l}\text { areAIO2 } \\
\text { areAIO2; bzuAI }\end{array}$ & ++ & $\begin{array}{l}++ \\
++\end{array}$ & + & + \\
\hline $\begin{array}{l}\text { areAIo2; bzuAI } \\
\text { areAIo2; gmdAI }\end{array}$ & \pm & ++ & \pm & \pm \\
\hline & \pm & $\frac{1}{+}$ & $\begin{array}{l}+ \\
+\end{array}$ & $\begin{array}{l}+ \\
+\end{array}$ \\
\hline$g m d A I$ & - & - & + & $T$ \\
\hline
\end{tabular}

* Added to $-\mathrm{N}$ medium.

† Added to $-\mathrm{CN}$ medium with ammonium chloride $\left(\mathrm{IO}^{-2} \mathrm{M}\right)$ as the sole nitrogen source.

Table 3. Acetamidase, benzamidase and phenylacetamidase activities under different growth conditions

\begin{tabular}{|c|c|c|c|c|}
\hline \multirow[b]{2}{*}{ Strain } & \multirow[b]{2}{*}{ Final growth conditions* } & \multicolumn{3}{|c|}{ Amidase specific activity $\dagger$} \\
\hline & & Acetamidase & Benzamidase & Phenylacetamidase \\
\hline \multirow[t]{3}{*}{ Wild type } & $\begin{array}{l}-\mathrm{N} \text { medium } \\
-\mathrm{N} \text { medium }+\end{array}$ & 20 & 24 & 12 \\
\hline & $5 \times 10^{-3} \mathrm{M}$-benzamide & 59 & 25 & 15 \\
\hline & $-\mathrm{CN}$ medium & 43 & NS & NT \\
\hline \multirow[t]{5}{*}{ areAlo2 } & $\begin{array}{l}-\mathrm{N} \text { medium } \\
-\mathrm{N} \text { medium }+\end{array}$ & 148 & 168 & 77 \\
\hline & $5 \times 10^{-3} \mathrm{M}$-benzamide & 96 & 80 & 38 \\
\hline & $\begin{array}{l}-\mathrm{CN} \text { medium } \\
-\mathrm{CN} \text { medium }+\end{array}$ & 62 & NS & NT \\
\hline & $\begin{array}{l}5 \times 10^{-3} \mathrm{M} \text {-benzamide } \\
-\mathrm{N} \text { medium }+\end{array}$ & 143 & NS & NS \\
\hline & $\begin{array}{l}5 \times 10^{-3} \mathrm{M} \text {-benzamide }+ \\
10^{-2} \mathrm{M} \text {-ammonium }\end{array}$ & 30 & NS & NS \\
\hline \multirow[t]{3}{*}{$\operatorname{areAIOL} ; \operatorname{gmdAI}$} & $\begin{array}{l}-\mathrm{N} \text { medium } \\
-\mathrm{N} \text { medium }+\end{array}$ & 179 & 15 & 13 \\
\hline & $\begin{array}{l}5 \times 10^{-3} \mathrm{M} \text {-benzamide } \\
-\mathrm{CN} \text { medium }+\end{array}$ & 167 & 30 & I 5 \\
\hline & $5 \times 10^{-3} \mathrm{M}$-benzamide & 196 & NS & NS \\
\hline \multirow[t]{2}{*}{$\operatorname{areA19}$} & $-\mathbf{N}$ medium & NS & NS & NT \\
\hline & $-\mathrm{CN}$ medium & 60 & NS & NT \\
\hline \multirow[t]{2}{*}{ areAIO2; bzuAI } & $\begin{array}{l}-\mathrm{N} \text { medium } \\
-\mathrm{N} \text { medium }\end{array}$ & 165 & 222 & 88 \\
\hline & $5 \times 10^{-3} \mathrm{M}$-benzamide & 87 & 85 & 43 \\
\hline
\end{tabular}

Ns, Non-significant activity (specific activity less than Io); NT, not tested.

* Mycelium grown for $16 \mathrm{~h}$ in $-\mathrm{N}$ medium $+1 \mathrm{I}^{-2} \mathrm{M}$-ammonium, then transferred to the indicated medium for a further $4 \mathrm{~h}$ incubation before harvesting.

$\dagger$ Expressed as nmol ammonium released/min/mg protein.

(Hynes, I973 $b, 1975 a$ ). The areAI9 strain lacked benzamidase activity (Table 3). Since areAIO2 has higher acetamidase and histidase levels than wild type while areAIg has lower levels of these enzymes than wild type (Hynes \& Pateman, I970a; Hynes, 1972, 1973 $b$, $1974 b$; Polkinghorne \& Hynes, 1975), the results indicate that benzamidase is controlled by $\operatorname{are} A$ in a similar way to acetamidase and histidase. The are $A$ gene is a regulatory gene 
involved in ammonium repression of enzymes of nitrogen catabolism (Arst \& Cove, 1973; Hynes, $1974 b, 1975 a$ ). Therefore it was expected that benzamidase and phenylacetamidase activity might be subject to ammonium repression. In agreement with this, are Aroz lacked amidase activity with these substrates when mycelium was incubated in the presence of benzamide and ammonium (Table 3). More extensive data regarding ammonium repression of benzamidase activity have been presented elsewhere (Hynes, 1974 $a, b$ ), and, in addition, evidence has been presented for glutamate and glutamine repression of benzamidase activity (Hynes, 1974b).

In contrast to acetamidase activity, benzamidase activity was extremely low when mycelium of all strains was incubated in medium lacking both a carbon and a nitrogen source or when benzamide $\left(5 \times 10^{-3} \mathrm{M}\right)$ was the sole carbon and nitrogen source (Table 3$)$. This indicated that benzamidase might not be subject to carbon catabolite regulation and, in fact, suggests that there may be a restriction on the synthesis of this enzyme under conditions of carbon starvation. There is evidence for a similar phenomenon with nitrate reductase (Hynes, I973 $a$ ) and histidase (Polkinghorne \& Hynes, 1975).

The areAIO2; gmdAI strain produced much less benzamidase and phenylacetamidase activity than the areArO2 strain, while acetamidase activity was unaffected (Table 3 ).This, together with the differences in regulation, indicated that benzamidase and phenylacetamidase activities were due to different enzymes from that of acetamidase. Further evidence for this is outlined below. Phenylacetamidase activity was approximately half that of benzamidase activity in all strains under all growth conditions investigated (Table 3 ). This suggested that benzamide and phenylacetamide were substrates for a single enzyme. This enzyme is hereafter called the general amidase.

In the wild-type strain the presence of benzamide in the $-\mathrm{N}$ medium did not increase the general amidase activity above the level present in mycelium incubated in $-\mathrm{N}$ medium alone (Table 3). This suggested a lack of induction by benzamide. Incubation of the are Aro2 strain in $-\mathrm{N}$ medium plus benzamide resulted in a lower general amidase activity than that present in $-\mathrm{N}$ medium alone. Lower acetamidase activity was also found under these conditions. These data were compatible with ammonium produced from benzamide via general amidase activity repressing both amidases. This was supported by the finding that this did not occur when $g m d A I$ was present (Table 3) and reinforced the conclusions that $g m d A I$ affected benzamidase activity in vivo and that the general amidase was subject to ammonium repression.

\section{Utilization of amides as nitrogen sources}

Strains with various combinations of the lesions affecting amidase activities were tested for their abilities to grow at $37^{\circ} \mathrm{C}$ on solid medium with various amides as sole nitrogen sources (Table 4). As noted previously (Hynes \& Pateman, I970 c) the $f m d S_{I}$ lesion had a major effect on growth on formamide, but not other amides, although very slight effects on benzamide utilization were observed (not shown in Table 4). This might have been due to release of formamide during benzamide breakdown via pathways other than benzamide hydrolysis. The amdSI lesion greatly affected the utilization of acetamide, and to a lesser extent the utilization of propionamide, butyramide, valeramide and hexanamide, but did not affect growth on benzamide. Very slight effects of $a m d S_{I 7}$ on phenylacetamide utilization were observed and this may have been due to acetamide release from phenylacetamide. As noted above, the presence of the gmdAI mutation led to an almost complete loss of the ability to utilize phenylacetamide and greatly reduced growth on benzamide. The leakiness of growth of gmdAI on benzamide increased with time of incubation (greater than 2 days) and may be due, in part, to breakdown of benzamide by pathways other than hydrolysis by 


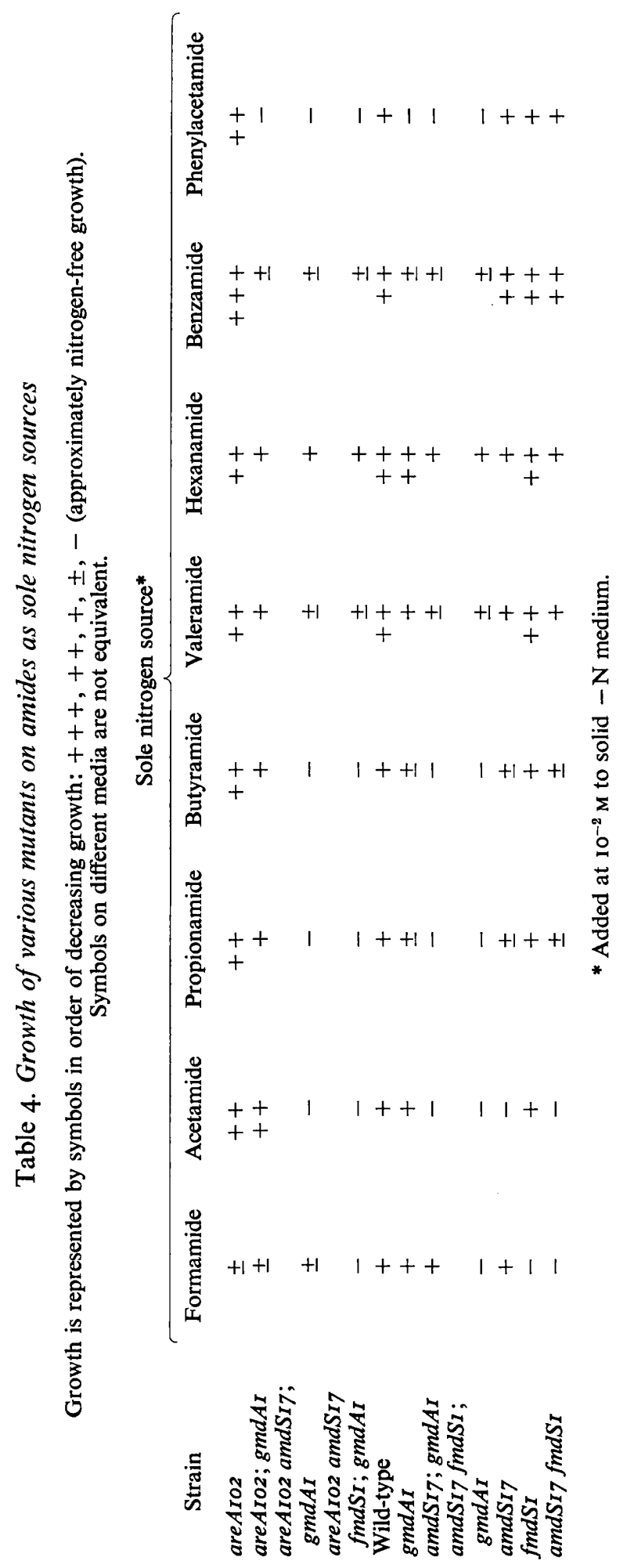


the general amidase. The $g m d A I$ lesion had no detectable effect on formamide or acetamide utilization, but did affect growth on propionamide, butyramide, valeramide and hexanamide.

Strains containing both $g m d A I$ and $a m d S_{I} 7$ mutations were greatly affected in the utilization of propionamide and butyramide, suggesting that the products of both of these genes were the major factors in the utilization of these amides. There was still substantial utilization of valeramide and hexanamide (particularly after prolonged incubation) by strains containing both amdSI7 and gmdAI lesions. This indicated that there might be yet another enzyme capable of hydrolysing these amides.

Growth of areAroz-containing strains on most amides as nitrogen sources was better than the corresponding are $A^{+}$strains, consistent with the higher acetamidase and general amidase activities found in areAIO2 strains (see above). The presence of areAroz leads to lowered levels of formamidase and to poor growth on formamide (Hynes \& Pateman, I970b).

The effects of $g m d A I$ on the utilization of other amides as nitrogen sources has been tested. These results indicated that nicotinamide, indoleacetamide, naphthaleneacetamide, anthranilamide, L-leucineamide, L-prolineamide and L-phenylalanineamide were utilized mainly via the general amidase affected by the $g m d A I$ lesion. Acetanilide and salicylamide were too toxic to be tested. Like acetamide, glycineamide utilization was affected by amd $S_{I 7}$ but not by $g m d A I$. The utilization of urea, asparagine and glutamine was not affected by $g m d A I, f m d S_{I}$ or $a m d S_{I 7}$ lesions.

\section{Utilization of amides as carbon sources}

Benzamide and phenylacetamide were poor sole carbon sources for $A$. nidulans, and benzamide could only be tested at relatively low concentrations (about $\mathrm{IO}^{-2} \mathrm{M}$ ) as it was toxic at higher concentrations; growth tests on these carbon sources were therefore not very efficient. However, it was clear that gmdAI had very little effect on the utilization of benzamide or phenylacetamide as carbon source. The presence of $f m d S_{I}$ and amdSI7 also had little effect on growth when benzamide was the carbon source. The presence of amdSI7 slightly reduced utilization of phenylacetamide as a carbon source, whereas fmdSI had little effect. These results suggested that these aromatic amides may be catabolized as carbon sources by pathways other than amidase hydrolysis.

The presence of $f m d S_{I}$ or $g m d A I$ did not affect the utilization of acetamide, propionamide, butyramide, valeramide or hexanamide as sole carbon source, whereas amdSI 7 greatly affected growth on acetamide, propionamide and butyramide as carbon sources. When valeramide and hexanamide were the sole carbon sources growth was slightly affected by amd $S_{I 7}$, but there was substantial growth on these amides by strains containing $a m d S_{I}$. Therefore it was likely that a fourth enzyme, in addition to the acetamidase, contributed to the utilization of valeramide and hexanamide as carbon sources; the same could be also concluded for valeramide and hexanamide utilization as nitrogen sources (see above).

\section{Amidase activities of multiple amidase mutants}

The results shown in Table 5 support the conclusions derived from growth tests. The strains containing $g m d A I$ had greatly reduced benzamidase activity. The $g m d A I$ lesions also resulted in substantially lower propionamidase, butyramidase and hexanamidase activities, but significant activities remained. Propionamidase and butyramidase activity was abolished in strains containing both $g m d A I$ and $a m d S_{I} 7$ lesions, suggesting that the acetamidase and general amidase enzymes were the major enzymes of utilization of these amides. Hexanamidase activity was only very slightly lowered by the presence of $a m d S_{I 7}$ in $g m d A I$-containing 


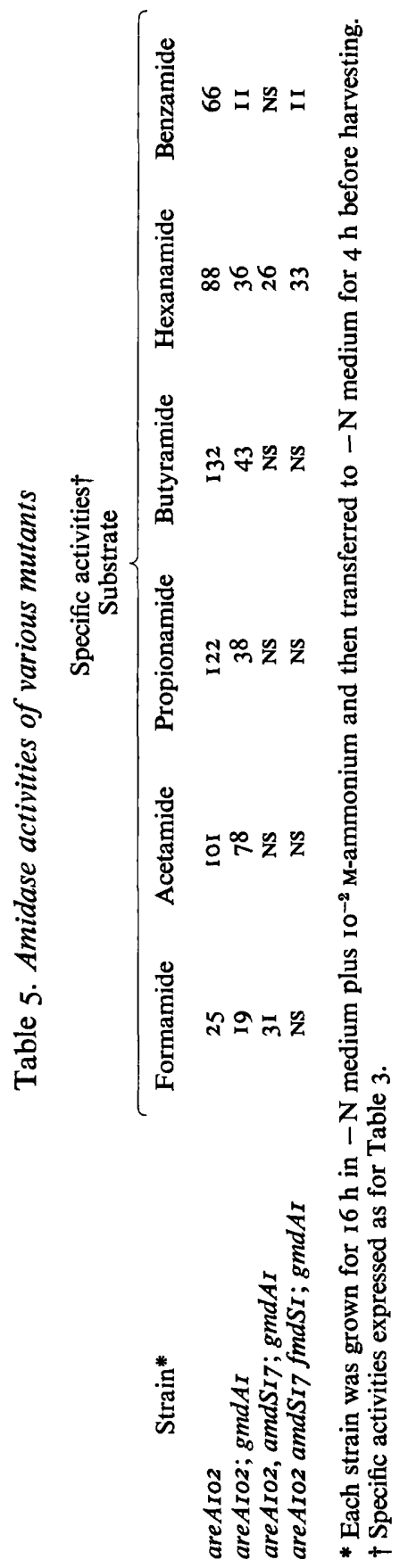




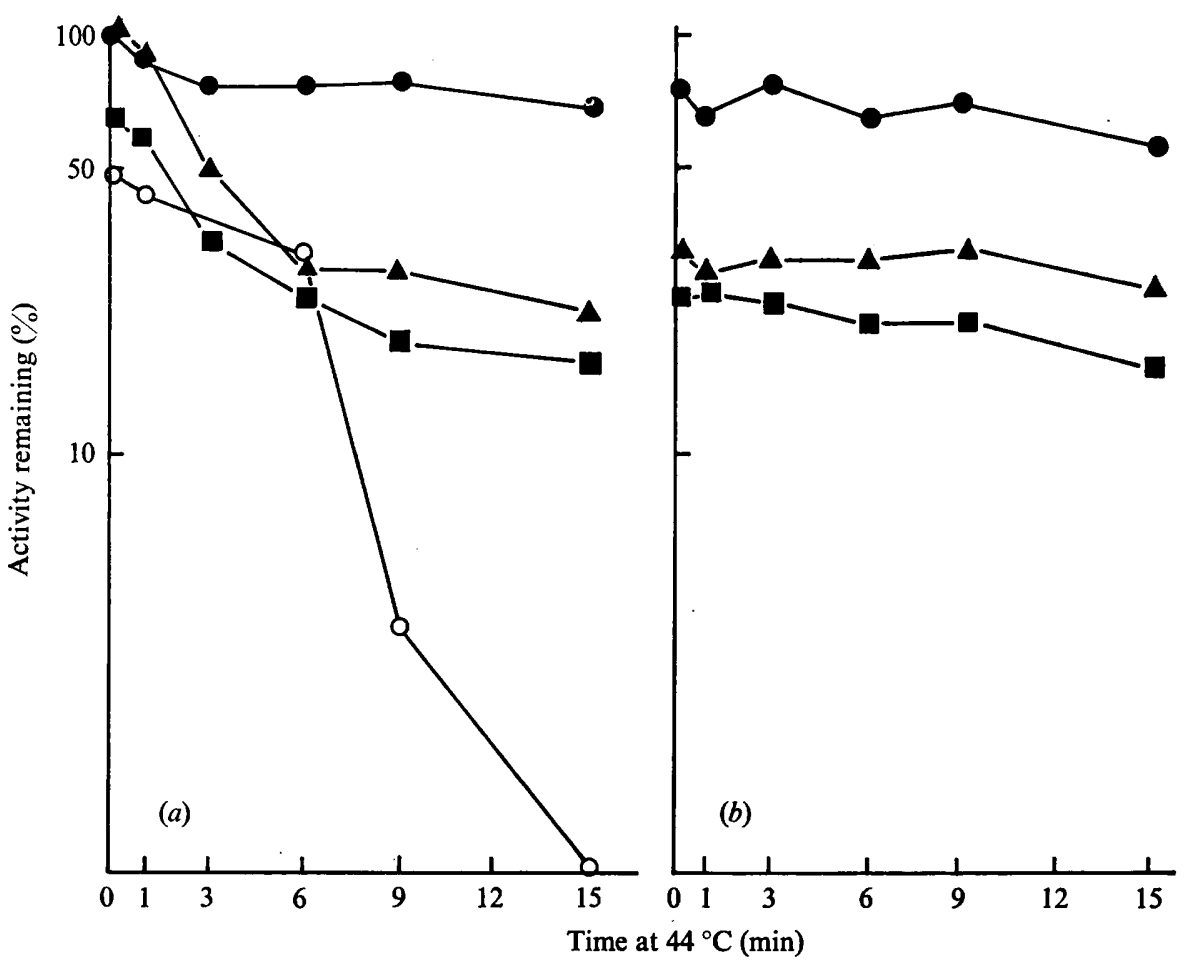

Fig. I. Thermal inactivation of amidase activities of crude extracts at $44^{\circ} \mathrm{C}$. Mycelium was grown for $16 \mathrm{~h}$ in $-\mathrm{N}+10^{-2} \mathrm{M}$-ammonium medium and then transferred to $-\mathrm{N}$ medium for $4 \mathrm{~h}$ before preparation of crude extracts. Extracts were subjected to heat treatment at $44^{\circ} \mathrm{C}$. (a) are $\mathrm{AIOZ}$ (b) are Aro2, gmdAr. ค, Acetamidase; $\Delta$, butyramidase: $\square$, hexanamidase; $\bigcirc$, benzamidase. Activities are expressed as a percentage of the acetamidase activity of the are Aroz extract which was not subjected to heat treatment.

strains, supporting the proposal that a fourth amidase enzyme capable of hexanamide hydrolysis existed. The $f m d S_{I}$ lesion abolished formamidase activity, while $g m d A r$ and amdSI 7 had little effect.

\section{Thermal inactivation studies on amidase enzymes}

Preliminary experiments indicated that benzamidase activity in crude extracts was more sensitive to heating than acetamidase activity. Therefore crude extracts of areAroz and are AIO2; gmdAI strains were incubated at $44{ }^{\circ} \mathrm{C}$ and amidase activities determined after various times of incubation (Fig. I). The data indicated that benzamidase activity was sensitive to heating at $44^{\circ} \mathrm{C}$, while acetamidase activity was relatively stable. Both butyramidase and hexanamidase activities of areA102; showed a heat-sensitive component which was abolished in the areAIO2; gmdAI strain. These results were compatible with the general amidase enzyme, affected by the gmd $A I$ lesion, contributing to butyramide and hexanamide hydrolysis but not significantly to acetamide hydrolysis.

\section{Gel electrophoresis studies}

Starch gel electrophoresis at pH 8.5 (see Methods) of crude extracts of the areAro2 strain incubated in $-\mathrm{N}$ medium for $4 \mathrm{~h}$ was performed. When acetamide was the substrate a single zone of enzyme activity was found. When benzamide was the substrate, a single 


\section{Table 6. Summary of the properties of amidase enzymes}

Nitrogen metabolite repression refers to mechanisms of control by the nitrogen metabolites, ammonium, glutamate and glutamine (Hynes, 1974b). Carbon catabolite repression refers to mechanisms of control by sucrose, glucose and other good carbon sources (Hynes, 1972; Arst \& Cove, 1973), and, in addition, to control by acetate (Arst \& Cove, 1973; Hynes, unpublished observations).

\begin{tabular}{|c|c|c|c|}
\hline Enzyme & Possible structural gene & Major substrates & Regulation \\
\hline Formamidase & fmdS & Formamide & $\begin{array}{l}\text { Nitrogen metabolite } \\
\text { repression, weak carbon } \\
\text { catabolite repression, } \\
\text { non-inducible }\end{array}$ \\
\hline Acetamidase & amdS & $\begin{array}{l}\text { Acetamide, propionamide, } \\
\text { butyramide, valeramide, } \\
\text { hexanamide }\end{array}$ & $\begin{array}{l}\text { Nitrogen metabolite } \\
\text { repression, carbon } \\
\text { catabolite repression, } \\
\text { inducible }\end{array}$ \\
\hline General amidase & $g m d S$ & $\begin{array}{l}\text { Benzamide, } \\
\text { phenylacetamide, } \\
\text { butyramide, valeramide, } \\
\text { hexanamide }\end{array}$ & $\begin{array}{l}\text { Nitrogen metabolite } \\
\text { repression, non-inducible }\end{array}$ \\
\hline
\end{tabular}

zone of activity, running just ahead of the acetamidase zone, was observed. With butyramide two zones of activity were observed, one corresponding to the acetamidase zone and the other to the benzamidase zone. These results were consistent with the conclusion that the acetamidase and general amidase were distinct, and that butyramide was a substrate for both enzymes.

\section{DISCUSSION}

The properties of the three amidases proposed in this paper are summarized and compared in Table 6. The possible fourth enzyme involved in valeramide and hexanamide utilization (see above) is not included. The acetamidase and general amidase enzymes have common substrates but are clearly distinct in their regulation, genetic determination and in some biochemical properties. The general amidase appears only to be involved in the utilization of amides as nitrogen sources, whereas acetamidase is responsible for the utilization of aliphatic amides as carbon or as nitrogen sources. The pathway of the utilization of benzamide and phenylacetamide as carbon sources is unknown. The role of the $b z u A$ gene is also not known, though it may be that it is the product of this gene that controls the uptake of both benzamide and benzoate.

The formamidase appears to be very specific for formamide. It is not clear why this enzyme should derepress to some extent when mycelium is incubated in medium lacking a carbon source (Hynes, 1972), since formamide cannot act as a carbon source for $A$. nidulans. The $f m d S I$ lesion abolishes this increase in formamidase activity upon carbon starvation, indicating that this activity is not due to a separate enzyme (Hynes, unpublished observations). Perhaps the $f m d S$ gene arose from the amdS gene by gene duplication, and subsequent divergence altered the $f m d S$ gene product to a specific formamidase without completely abolishing the sensitivity of this enzyme to carbon catabolite repression.

Brady (1969) described an enzyme from Candida utilis with hydrolytic activity towards a very wide range of amide substrates, including acetamide and benzamide. Extensive studies have shown that Pseudomonas aeruginosa possesses an amidase of limited substrate range, but this range has been modified and extended by laboratory selection of structural gene 
mutants (for review see Betz et al. 1974). Other species of Pseudomonas may possess more than one enzyme with amidase activities (Clarke, 1974).

Clearly, purification and detailed comparison of the amidase enzymes of $A$. nidulans is needed. It may be of great interest to explore possible evolutionary relationships between the enzymes, particularly in view of the differences in the regulation of these enzymes.

Technical assistance by Iole Barbieri and Jan Dickinson is greatly appreciated. This work has been supported by the Australian Research Grants Committee.

\section{REFERENCES}

ARST, H. N. \& CovE, D. J. (1969). Methylammonium resistance in Aspergillus nidulans. Journal of Bacteriology 98, 1284-I 293.

ARST, H. N. \& Cove, D. J. (1973). Nitrogen metabolite repression in Aspergillus nidulans. Molecular and General Genetics 126, I I I-I4I.

BRADY, B. L. (1969). The acylamide amidohydrolase of Candida utilis: purification and properties. Journal of General Microbiology 59, 47-55.

Betz, J. L., Brown, P. R., Smyth, M. J. \& Clarke, P. H. (1974). Evolution in action. Nature, London 247, 26I-264.

Clarke, P. H. (1974). Amidases of Pseudomonas species. Biochemical Society Transactions 2, 83I-834.

Clutterbuck, A. J. (1973). Gene symbols in Aspergillus nidulans. Genetical Research 21, 29I-296.

Cove, D. J. (1966). The induction and repression of nitrate reductase in the fungus Aspergillus nidulans. Biochimica et biophysica acta 113, 51-56.

Dunsmuir, P. \& Hynes, M. J. (1973). Temperature sensitive mutants affecting the activity and regulation of the acetamidase of Aspergillus nidulans. Molecular and General Genetics 123, 333-346.

GAHNE, B. (1963). Inherited variations in the post-albumins of cattle serum. Hereditas 50, 126-135.

HyNes, M. J. (1972). Mutants with altered glucose repression of amidase enzymes in Aspergillus nidulans. Journal of Bacteriology III, 71 7-722.

Hynes, M. J. (1973a). The effect of lack of a carbon source on nitrate-reductase activity in Aspergillus nidulans. Journal of General Microbiology 79, $155-157$.

HYNES, M. J. (I $1973 b$ ). Pleiotropic mutants affecting control of nitrogen metabolism in Aspergillus nidulans. Molecular and General Genetics 125, 99-107.

HyNES, M. J. (1974a). Repression of enzymes of nitrogen catabolism by methylammonium and caesium chloride in strains of Aspergillus nidulans insensitive to ammonium repression. Molecular and General Genetics 132, I47-I52.

HyNES, M. J. (1974b). Effects of ammonium, L-glutamate, and L-glutamine on nitrogen catabolism in Aspergillus nidulans. Journal of Bacteriology 120, I I $16-1 \mathrm{I} 23$.

HyNEs, M. J. (1975a). Studies on the role of the areA gene in the regulation of nitrogen catabolism in Aspergillus nidulans. Australian Journal of Biological Sciences 28, 301-313.

Hynes, M. J. (1975b). Benzamide inhibited mutants of A. nidulans. Aspergillus Newsletter 12, I6-17.

Hynes, M. J. \& PATEMAN, J. A. (1970a). The use of amides as nitrogen sources by Aspergillus nidulans. Journal of General Microbiology 63, 317-324.

Hynes, M. J. \& Pateman, J. A. (1970b). The genetic analysis of regulation of amidase synthesis in Aspergillus nidulans. I. Mutants able to utilize acrylamide. Molecular and General Genetics 108, 97-106.

Hynes, M. J. \& Pateman, J. A. (1970c). The genetic analysis of regulation of amidase synthesis in Aspergillus nidulans. II. Mutants resistant to fluoroacetamide. Molecular and General Genetics ro8, I07-I 16.

Lowry, O. H., Rosebrough, M. J., Farr, A. L. \& Randall, R. J. (I95I). Protein measurement with the Folin phenol reagent. Journal of Biological Chemistry r93, 265-275.

Mackintosh, M. E. \& Pritchard, R. H. (I963). The production and replica-plating of micro-colonies of Aspergillus nidulans. Genetical Research 4, 320-322.

MCCulLy, K. S. \& Forbes, E. (1965). Use of $p$-fluorophenylalanine with master strains of Aspergillus nidulans. Genetical Research 6, 352-359.

Polkinghorne, M. \& HyNes, M. J. (1975). Mutants affecting histidine utilization in Aspergillus nidulans. Genetical Research 25, (in the Press). 